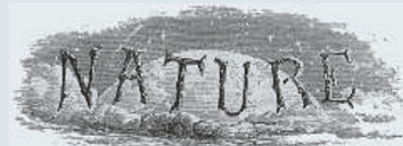

\section{YEARS AGO}

With the appearance of a new journal, Virology (pp. 140. New York: Academic Press, Inc.; 9 dollars per vol.), this useful, but ugly, word of doubtful parentage presumably takes its place as the official designation of the study of viruses.

From Nature 9 July 1955.

\section{YEARS AGO}

Even with things as they are, Oxford and Cambridge, though much injured by competitive examinations, have been far less injured than England in general; and this they owe to the residential system. Little thought of, perhaps neglected, by the builders, the head-stone of the educational edifice is here to be found. Where mind meets mind in the free intercourse of youth there springs from the contact some of the fire which, under our present system, is rarely to be obtained in any other way; and not only this, but many other priceless advantages in the battle for life are also conferred. To these influences we owe in large part all that is best in the English character, and so valuable are the qualities thus developed, or at least greatly strengthened, that we regard residential colleges as essential to the success and usefulness of the newer universities.

\section{ALSO:}

An Angler's Hours. By H. T. Sherringham. Mr. Sherringham deserves the thanks of all anglers who have an idle hour and no fishing for having re-published his essays in book form, and he who is forced by sad circumstance to enjoy his fishing vicariously will find his time well spent in our scribe's company... he despairs of nothing, but finds good in all; if there are no fish he can study nature, and if there is no water he can shrewdly meditate on the ways of fish and men; an hour with him and his rod by a troutless tarn is as good as an hour by the Kennet in the mayfly time... A word of praise is also due to the publishers, who have produced a book the size and print of which add to its convenience as an adjunct to a pipe, an easy chair, and idleness.

From Nature 6 July 1905.

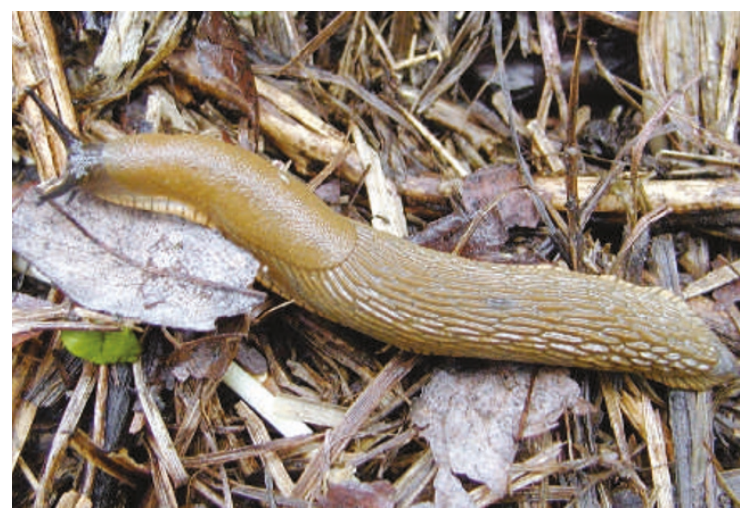

Figure 1 Arion lusitanicus — conservation agent.

grassland sown with rye grass (Lolium perenne) and white clover (Trifolium repens) on a former arable field that contained its own residual seed bank of weed and other plant species.

The surface soil was thoroughly mixed to avoid local patchiness in the seed bank, and a series of experimental $2 \times 2$-m plots was established, each surrounded by a slug-proof fence. Local slugs were placed in selected plots at a density of 22 individuals per plot during the first year, with an additional 10 slugs in subsequent years; this represents a high but realistic concentration of the molluscs. Wooden slug shacks provided shelter for these easily desiccated creatures in times of drought. The control plots were treated with molluscicide to prevent any inadvertent slug invasion. Analysis of the vegetation composition over the following three years provided the data needed to determine the effect of slug grazing.

In the first two years, the species richness and the diversity were lower in the slug-grazed plots than in controls. (Species richness is the number of species per plot; diversity also takes into account the proportions of different species, and is measured by the Shannon diversity index.) This result confirms the expectation that slug selection of seedlings would reduce the number of $z$ species from the local seed bank that become established. In the third year of the experiment, however, species richness in the grazed plots was $23 \%$ higher than in the controls.

The reason for this enhancement of richness and diversity in the more mature stages can be attributed to the consistent removal of biomass by the slugs. The yield from primary productivity was reduced by around $25 \%$ as a result of slug grazing (comparable to the removal of biomass by sheep in a grazed pasture ${ }^{4}$ ). Holding back the development of dominance by fast-growing species provided an opportunity for the germination and establishment of less-competitive species, including annual plants. In other words, slug grazing permits the establishment of plant species that might otherwise find it difficult to maintain populations in developing grassland. So, on this account at least, slugs are good for diversity.

Slugs will never act as sheep substitutes by creating a pastorally idyllic landscape and inspiring poets. But they could well be an answer to the conservationist's prayer silently grazing beneath our feet, they provide an alternative way to mow a meadow.

Peter D. Moore is in the Division of Life Sciences, King's College London, Franklin-Wilkins Building, 150 Stamford Street, London SE1 9NH, UK. e-mail: peter.moore@kcl.ac.uk

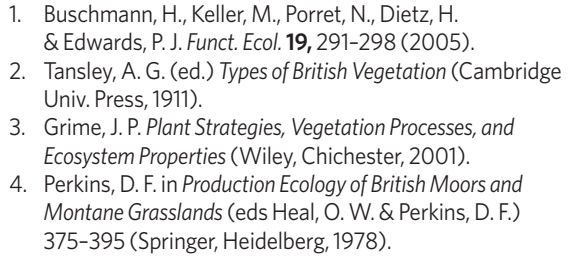

\title{
NONLINEAR DYNAMICS
}

\section{When instability makes sense}

\author{
Peter Ashwin and Marc Timme
}

\section{Mathematical models that use instabilities to describe changes of weather patterns or spacecraft trajectories are well established. Could such principles apply to the sense of smell, and to other aspects of neural computation?}

Dynamical stability is ubiquitous in many systems - and more often than not is desirable. Travelling down a straight road, a cyclist with stable dynamics will continue in more or less a straight line despite a gust of wind or a bumpy surface. In recent years, however, unstable dynamics has been identified not only as being present in diverse processes, but even as being beneficial. A further exciting candidate for this phenomenon is to be found in the realm of neuroscience - mathematical models ${ }^{1-3}$ now hint that instabilities might also be advantageous in representing and processing information in the brain.

A state of a system is dynamically stable when it responds to perturbations in a proportionate way. As long as the gust of wind is not too strong, our cyclist might wobble, but the 